\title{
Posttraumatic stress disorder and employment in veterans participating in Veterans Health Administration Compensated Work Therapy
}

\author{
Sandra G. Resnick, PhD; ${ }^{*}$ Robert A. Rosenheck, MD $^{2}$ \\ ${ }^{1}$ New England Mental Illness Research, Education, and Clinical Center, Veterans Integrated Services Network 1, \\ Department of Veterans Affairs, New Haven, CT; ${ }^{2}$ Department of Psychiatry, Yale University School of Medicine, New \\ Haven, CT
}

\begin{abstract}
Few studies have examined employment outcomes in individuals with a primary diagnosis of posttraumatic stress disorder (PTSD). The current study used multivariate modeling to examine the relationship between PTSD, other aspects of military service, and employment among 5,862 veterans in a national Department of Veterans Affairs (VA) vocational rehabilitation program. Veterans with PTSD were $19 \%$ less likely to be employed at discharge (odds ratio $=0.81, p=0.02$ ) after controlling for potentially confounding variables. Individuals with substance use diagnoses or who were homeless at program entry were more likely to be employed at discharge, while receipt of public support income and severe mental illness decreased the likelihood of being competitively employed. This study supports current VA efforts to expand and improve the effectiveness of vocational rehabilitation services for veterans with PTSD.
\end{abstract}

Key words: CWT, dissemination, employment, implementation, psychiatric rehabilitation, PTSD, supported employment, veterans, vocational rehabilitation, work.

\section{INTRODUCTION}

Vocational rehabilitation services for people with serious mental illness, especially supported employment (SE), are increasingly considered to be central features of a "recovery-oriented" service system [1]. While the evidence for SE for people with severe mental illnesses such as schizophrenia and bipolar disorder is strong [2], much less is known about individuals with a primary diagnosis of posttraumatic stress disorder (PTSD) participating in vocational rehabilitation.

Several studies have examined the relationship between PTSD and employment outside of vocational services. One population-based survey of Vietnam-era veterans found that those with combat-related PTSD were significantly less likely to be employed than those without PTSD and PTSD diagnosis was associated with a lower hourly wage among those in the competitive workforce [3]. In a cross-sectional study of veterans with PTSD beginning a clinical trial, increased severity of PTSD was associated with a decreased likelihood of fulltime employment [4]. Magruder et al. also found an association between PTSD severity and unemployment in veterans receiving primary care services [5].

Abbreviations: CWT $=$ Compensated Work Therapy, FY $=$ fiscal year, NEPEC = Northeast Program Evaluation Center, PTSD = posttraumatic stress disorder, SD = standard deviation, $\mathrm{SE}=$ supported employment, TWE = transitional work experience, VA = Department of Veterans Affairs, VHA = Veterans Health Administration.

*Address all correspondence to Sandra G. Resnick, PhD; VA Connecticut Healthcare System, NEPEC (182), 950 Campbell Ave, West Haven, CT 06516; 203-932-5711, ext 5106; fax: 203-937-3433. Email: sandy.resnick@yale.edu

DOI: 10.1682/JRRD.2007.06.0093 
We located only two studies that examined outcomes of individuals with PSTD participating in vocational rehabilitation. In the first, two groups of veterans with PTSD participating in a Department of Veterans Affairs (VA) specialized PTSD treatment program were compared: those enrolled in Compensated Work Therapy (CWT), a VA vocational rehabilitation program, and a matched sample of those not enrolled in CWT [6]. At a 4-month follow-up, no differences existed in employment status between the two groups. Mueser et al. conducted a secondary analysis of data from a randomized trial comparing three different vocational programs for people with severe mental illness [7]. Of the sample, 16 percent $(n=28)$ met criteria for PTSD in addition to at least one other Axis I psychiatric disorder. Within those randomly assigned to receive SE, individuals with a comorbid diagnosis of PTSD worked significantly less than those without a PTSD diagnosis during the SE intervention [7].

The current study seeks to examine the employment status of veterans with PTSD during participation in and at discharge from CWT. In view of the current interest in veterans returning from Operation Iraqi Freedom and Operation Enduring Freedom, we pay particular attention to service in a theater of operations (war zone), especially among veterans who served in these two conflicts. Recognizing that the phenomenological experience of PTSD may vary by both service era and by war zone service, we have chosen an analytic strategy that allows us to examine the independent effects of all three of these variables (PTSD, service era, and war zone service) in a single model, with adjustment for other potentially influential factors. First, we examined the bivariate relationship between veteran characteristics and competitive employment at discharge. Factors examined include PTSD, service era, service in a wartime theater of operations, sociodemographic characteristics, and disability income. Second, we examined the relationship between competitive employment and the three primary outcome variables of interest in a single multivariate model. Multivariate analysis is preferable to a series of separate models examining PTSD, service era, and war zone service because it allows a more parsimonious analysis of the independent effects of these three variables on employment. Lastly, to further explore these group differences we compared measures of CWT participation between those with and without PTSD diagnoses.

\section{METHODS}

\section{Veterans Health Administration CWT Program}

The Veterans Health Administration (VHA) CWT program provides diverse vocational approaches, with 163 individual programs in VHA facilities nationwide that follow multiple models of vocational rehabilitation. Despite the structural and philosophical variability of CWT programs, until recently the predominant vocational activity in CWT has been the transitional work experience (TWE) [8]. As described in more detail later in this section, since 2004, SE for veterans with severe mental illness has become a growing part of CWT at all sites nationwide.

In the TWE component of CWT (CWT/TWE), employers contract with the CWT program to fill job openings or to perform identified tasks. The veteranworkers are hired by CWT, and although vocational staff may provide job coaching or other types of support, they are often also supervised directly by the employer. The employee's wages are paid by CWT, and participating companies pay a small surcharge to support program operations. Some TWE positions are located in community businesses, but the majority of contracts for TWEs are between CWT and their parent VA medical center, such that veterans work in such positions as janitors, print shop workers, construction workers, and groundskeepers for the facility at which they also receive treatment. CWT/TWE programs across VHA vary considerably in program structure, philosophy, and focus.

$\mathrm{SE}$ is a new vocational service component offered within CWT and has been designed to follow the evidencebased Independent Placement and Support model of SE [9]. The CWT/SE model was developed to assist individuals with severe mental illnesses obtain employment in permanent jobs in the competitive economy. For those interested in working in competitive jobs, CWT/SE vocational specialists assist in identifying and obtaining positions based on individualized preferences and skills and then provide ongoing support and vocational assistance [9]. In contrast to TWEs, in CWT/SE the worker "owns" the job and is paid directly by the employer.

\section{Data Source}

As part of the performance monitoring of VA mental health programs, the VA Northeast Program Evaluation Center (NEPEC) has collected administrative data on participants in CWT programs since 1993 [8]. Individual 
veteran data are collected by vocational rehabilitation specialists via clinical interview, chart review, and the financial records of CWT. In 2006, an electronic datacollection system was implemented that is located on the VA's intranet, ensuring that only those with a VA network connection and valid login can access the system [10]. The current study is based on all available data gathered through this new system at the time of analysis and includes admission and discharge forms from the electronic system for fiscal year (FY) 2006 and the first half of FY 2007.

The admission form, as the name implies, is administered when a veteran is admitted to the CWT program and documents sociodemographic and clinical characteristics of veterans at entry to the program. The discharge summary documents veteran outcomes, including competitive employment status, the date and reasons for discharge, income (including changes in benefits and compensation since program admission), housing status, employment status at discharge, clinical improvement, and plans for clinical follow-up. The summary also documents participation in paid employment (including TWE and SE) in the 90 days prior to discharge.

\section{Measures}

All variables are derived from the NEPEC electronic system database for FY 2006 and the first half of FY 2007 (through March 2007). Background characteristics assessed at admission to CWT include age, race/ethnicity, sex, years of formal education, military service era, service in a war zone (theater of operations), marital status, homelessness status, receipt of public support income, recent work history, number of medical conditions, and legal history. Diagnoses were assigned by CWT staff, who commonly obtain this information from the medical record. For the purposes of this study, severe mental illness is defined as a diagnosis of schizophrenia, schizoaffective disorder, bipolar disorder, or another psychotic disorder. The diagnosis of "affective disorder" is thus used for all affective disorders other than bipolar disorder.

The primary dependent variable is competitive employment at discharge from CWT, which is based on a single question: "Veteran's employment status at the time of discharge from CWT was...?” Participants are considered to be working competitively if either "full-time competitive employment in community" or "part-time competitive employment in community" is selected. At discharge, data on employment are also collected for the last 90 days of CWT participation.

\section{Sample}

We selected the sample using two criteria. First, we selected only those with completed episodes of care; that is, an episode for which an admission form was completed with a corresponding discharge form linked by Social Security number. Second, we excluded those who served in eras earlier than the Vietnam era because older veterans are less likely to be engaged in the competitive workforce [11]. We restricted the sample by service era rather than by age to best examine the relationship between service era and employment. Of the 6,038 completed episodes, we excluded 176 records because of preVietnam-era military service, leaving a final sample of 5,862 veterans from 122 CWT programs nationwide who had completed episodes.

\section{Data Analysis}

We ran descriptive statistics to examine the characteristics of the sample. We conducted bivariate analyses on admission characteristics to examine unadjusted differences in discharge competitive employment status, followed by a logistic regression to examine the adjusted (multivariate) relationship between admission characteristics, PTSD diagnosis, service era, theater of operations, and competitive employment status at discharge. Interactions between PTSD diagnosis and military service were also examined in the multivariate model. Finally, we compared those with and without PTSD on vocational activity in the 90 days prior to discharge. We obtained approval from the relevant institutional review boards prior to study initiation.

\section{RESULTS}

\section{Sample Characteristics}

As displayed in Table 1, the mean \pm standard deviation (SD) age of the sample was $48.2 \pm 7.2$ years and the veterans had spent a mean of $12.9 \pm 1.5$ years in formal schooling. Most participants were male (94.5\%), as is characteristic of a veteran sample; either Caucasian (47.6\%) or African American (48.5\%); and separated, widowed or divorced (59.2\%). The majority of the sample had served in the post-Vietnam era (54.4\%), with 34.7 percent from the Vietnam era and the remainder 
JRRD, Volume 45, Number 3, 2008

Table 1.

Competitive employment outcomes by admission characteristics.

\begin{tabular}{|c|c|c|c|c|}
\hline \multirow[b]{2}{*}{ Admission Characteristic } & \multicolumn{2}{|c|}{ Employment Outcome, $n$ (\%) } & \multirow[b]{2}{*}{$\begin{array}{c}\text { Total } \\
(N=5,862)\end{array}$} & \multirow[b]{2}{*}{ Test of Significance } \\
\hline & $\begin{array}{l}\text { Not Employed } \\
(n=3,800)\end{array}$ & $\begin{array}{r}\text { Employed } \\
(n=2,062)\end{array}$ & & \\
\hline Marital Status & & & & $\chi^{2}(2)=4.04^{*}$ \\
\hline Married/Remarried & $483(12.7)$ & 275 (13.3) & $758(12.9)$ & \\
\hline Separated, Widowed, Divorced & 2,225 (58.6) & $1,245(60.4)$ & $3,470(59.2)$ & \\
\hline Never Married & $1,092(28.7)$ & $542(26.3)$ & 1,634 (27.9) & \\
\hline Sex & & & & $\chi^{2}(1)=0.31^{*}$ \\
\hline Male & $3,586(94.4)$ & 1,953 (94.7) & $5,539(94.5)$ & \\
\hline Female & $214(5.6)$ & 109 (5.3) & $323(5.5)$ & \\
\hline Ethnicity & & & & $\chi^{2}(3)=2.61^{*}$ \\
\hline Caucasian & $1,782(46.9)$ & 1,009 (48.9) & 2,791 (47.6) & \\
\hline African-American & $1,866(49.1)$ & $978(47.4)$ & $2,844(48.5)$ & \\
\hline Hispanic & $48(1.3)$ & $26(1.3)$ & $74(1.3)$ & \\
\hline Other & $104(2.7)$ & $49(2.4)$ & $153(2.6)$ & \\
\hline Service Era & & & & $\chi^{2}(2)=41.65^{\dagger}$ \\
\hline Vietnam & $1,428(37.6)$ & 608 (29.5) & 2,036 (34.7) & \\
\hline Post-Vietnam & $1,925(50.7)$ & $1,147(55.6)$ & $3,072(54.4)$ & \\
\hline Persian Gulf & 447 (11.8) & 307 (14.9) & 754 (12.9) & \\
\hline Served in Vietnam & & & & $\chi^{2}(1)=1.23^{*}$ \\
\hline No & 3,316 (87.3) & 1,820 (88.3) & $5,136(87.6)$ & \\
\hline Yes & $484(12.7)$ & $242(11.7)$ & $726(12.4)$ & \\
\hline Served in Persian Gulf & & & & $\chi^{2}(1)=7.95^{\ddagger}$ \\
\hline No & 3,592 (94.5) & 1,911 (92.7) & 5,503 (93.9) & \\
\hline Yes & $208(5.5)$ & $151(7.3)$ & $359(6.1)$ & \\
\hline Served in Afghanistan & & & & $\chi^{2}(1)=0.02^{*}$ \\
\hline No & 3,775 (99.3) & 2,049 (99.4) & $5,824(99.4)$ & \\
\hline Yes & $25(0.7)$ & $13(0.6)$ & $38(0.7)$ & \\
\hline Served in Iraq & & & & $\chi^{2}(1)=2.80^{*}$ \\
\hline No & 3,737 (98.3) & 2,015 (97.7) & 5,752 (98.1) & \\
\hline Yes & $63(1.7)$ & $47(2.3)$ & $110(1.9)$ & \\
\hline Served in Other & & & & $\chi^{2}(1)=1.64^{*}$ \\
\hline No & 3,687 (97.0) & 1,988 (96.4) & $5,675(96.8)$ & \\
\hline Yes & $113(3.0)$ & $74(3.6)$ & $187(3.2)$ & \\
\hline Any Service-Connected Disability & & & & $\chi^{2}(1)=13.43^{\dagger}$ \\
\hline No & 3,009 (79.3) & $1,710(83.3)$ & $4,719(80.7)$ & \\
\hline Yes & $786(20.7)$ & $344(16.8)$ & $1,130(19.3)$ & \\
\hline Any Social Security Disability Income & & & & $\chi^{2}(1)=87.99^{\dagger}$ \\
\hline No & 3,350 (88.2) & $1,971(95.6)$ & $5,321(90.8)$ & \\
\hline Yes & $447(11.8)$ & $90(4.4)$ & $537(9.2)$ & \\
\hline Homeless When Last in Community & & & & $\chi^{2}(1)=11.80^{\dagger}$ \\
\hline No & $1,511(39.8)$ & $726(35.2)$ & 2,237 (38.2) & \\
\hline Yes & $2,288(60.2)$ & $1,336(64.8)$ & $3,624(61.8)$ & \\
\hline Posttraumatic Stress Disorder Diagnosis & & & & $\chi^{2}(1)=12.79^{\dagger}$ \\
\hline No & 3,128 (82.9) & $1,773(86.5)$ & 4,901 (84.1) & \\
\hline Yes & $647(17.1)$ & $278(13.6)$ & 925 (15.9) & \\
\hline Substance Use Diagnosis & & & & $\chi^{2}(1)=2.06^{*}$ \\
\hline No & $706(18.6)$ & $352(17.1)$ & $1,058(18.1)$ & \\
\hline Yes & $3,094(81.4)$ & $1,710(82.9)$ & $4,804(82.0)$ & \\
\hline Affective Disorder & & & & $\chi^{2}(1)=3.78^{\S}$ \\
\hline No & 2,539 (66.8) & 1,429 (69.3) & 3,968 (67.7) & \\
\hline Yes & 1,261 (33.2) & 633 (30.7) & 1,894 (32.3) & \\
\hline
\end{tabular}


Table 1. (Continued)

Competitive employment outcomes by admission characteristics.

\begin{tabular}{|c|c|c|c|c|}
\hline \multirow[b]{2}{*}{ Admission Characteristic } & \multicolumn{2}{|c|}{ Employment Outcome, $n$ (\%) } & \multirow[b]{2}{*}{$\begin{array}{c}\text { Total } \\
(N=5,862)\end{array}$} & \multirow[b]{2}{*}{ Test of Significance } \\
\hline & $\begin{array}{c}\text { Not Employed } \\
(n=3,800)\end{array}$ & $\begin{array}{c}\text { Employed } \\
(n=2,062)\end{array}$ & & \\
\hline Severe Mental Illness & & & & $\chi^{2}(1)=62.3^{\dagger}$ \\
\hline No & 2,955 (77.8) & $1,779(86.3)$ & $4,734(80.8)$ & \\
\hline Yes & 845 (22.2) & $283(13.7)$ & $1,128(19.2)$ & \\
\hline Ever Been Incarcerated & & & & $\chi^{2}(2)=19.64^{\dagger}$ \\
\hline No & $1,241(32.7)$ & $778(37.8)$ & $2,019(34.5)$ & \\
\hline Yes, <2 Weeks & $624(16.4)$ & $353(17.1)$ & 977 (16.7) & \\
\hline \multirow[t]{2}{*}{ Yes, $\geq 2$ Weeks } & $1,935(50.9)$ & $930(45.1)$ & 2,865 (4 8.9) & \\
\hline & Mean \pm SD & Mean \pm SD & Mean \pm SD & \\
\hline Age (yr) & $48.6 \pm 7.2$ & $47.6 \pm 7.3$ & $48.2 \pm 7.2$ & $t(5,817)=4.85^{\dagger}$ \\
\hline Education (yr) & $12.8 \pm 1.5$ & $12.9 \pm 1.5$ & $12.9 \pm 1.5$ & $t(5,839)=-1.5^{*}$ \\
\hline Worked for Pay 30 d Prior to Admission (d) & $0.8 \pm 3.5$ & $1.1 \pm 4.2$ & $0.9 \pm 3.7$ & $t(3,605)=-1.58^{\dagger}$ \\
\hline Public Support Income (\$) & $300.42 \pm 599.20$ & $137.42 \pm 344.61$ & $242.86 \pm 529.37$ & $t(5,803)=13 \cdot 17^{\dagger}$ \\
\hline Medical Conditions Reported (No.) & $1.5 \pm 1.4$ & $1.1 \pm 1.2$ & $1.4 \pm 1.3$ & $t(4,709)=9.34^{\dagger}$ \\
\hline $\begin{array}{l}\text { Note: Some sample sizes vary because of missing } \\
{ }^{*} \text { Not significant. } \\
{ }^{\dagger} p<0.001 . \\
{ }^{\ddagger} p=0.005 . \\
{ }^{\S_{p}} p=0.05 . \\
\text { SD }=\text { standard deviation. }\end{array}$ & & & & \\
\hline
\end{tabular}

(12.9\%) from the current era, the Persian Gulf era. Almost one-quarter of the sample served in a theater of operations: 12.4 percent in Vietnam, 6.1 percent in the Persian Gulf, 0.7 percent in Afghanistan, 1.9 percent in Iraq, and 3.2 percent in another theater of operations. Almost 16 percent of the sample had a PTSD diagnosis. The most common diagnosis was substance abuse (82.0\%); 32.3 percent had an affective disorder and 19.2 percent had a severe mental illness. At admission, 61.8 percent were homeless, 19.3 percent received VA benefits or compensation, and 9.2 percent received Social Security benefits, earning a mean \pm SD of $\$ 242.86 \pm \$ 529.37$ a month in public support income.

\section{Competitive Employment at Discharge}

We next examined bivariate differences in characteristics at program entry by competitive employment outcomes at discharge (Table 1). Individuals who were competitively employed were more likely to be younger, worked more days for pay prior to CWT admission, earned less public support income, and had fewer med- ical conditions. Those competitively employed at discharge were also more likely to have served in the postVietnam era or the Persian Gulf era, to have served in the Persian Gulf theater of operations, and to have been homeless when last living in the community. Veterans who were working competitively at discharge were less likely to be receiving VA service-connected disability income or Social Security income and less likely to have a diagnosis of PTSD, an affective disorder, a severe mental illness, or been incarcerated. The rate of competitive employment at discharge was 30 percent for individuals with PTSD and 36 percent for individuals without PTSD.

A multivariate model examining the relationship between admission characteristics and discharge competitive employment status is presented in Table 2. After controlling for all other independent variables, veterans with PTSD were 19 percent less likely to be employed at discharge (odds ratio $=0.81$, confidence interval $=0.69-0.96$ ) .

Several other significant associations emerged. Those who were never married were less likely to be competitively employed than those who were currently 
married, and veterans who served in the post-Vietnam era were more likely to have secured competitive employment at discharge than those who served in the Vietnam era, even after controlling for age, as were those who served in the Persian Gulf era. Veterans who served in any theater of operations were more likely to be employed. Presence of a substance abuse diagnosis or a diagnosis of an affective disorder was not significantly related to competitive employment status, although the likelihood of employment was decreased for veterans with a severe mental illness. Consistent with past research [12-13], individuals receiving public support income were significantly less likely to be employed, although this relationship was stronger for those receiving Social Security disability payments than for those receiving VA serviceconnected compensation. Veterans with a history of homelessness when last in the community had an increased likelihood of competitive employment at discharge, and there was a positive relationship between the number of days competitively employed prior to admission and the likelihood of competitive employment at discharge.

We further explored the relationship between employment and PTSD by examining interactions with service era, war zone service, and, specifically, service in the Iraq theater of operations. One significant interaction was found: those who had served in the post-Vietnam era and had PTSD were less likely than those with PTSD who served in the Vietnam era to work competitively at discharge.

\section{Predischarge Program Participation and Employment}

No significant differences existed in the proportion of veterans who were employed in any work activity during

Table 2.

Logistic regression of admission characteristics on employment outcomes at discharge.

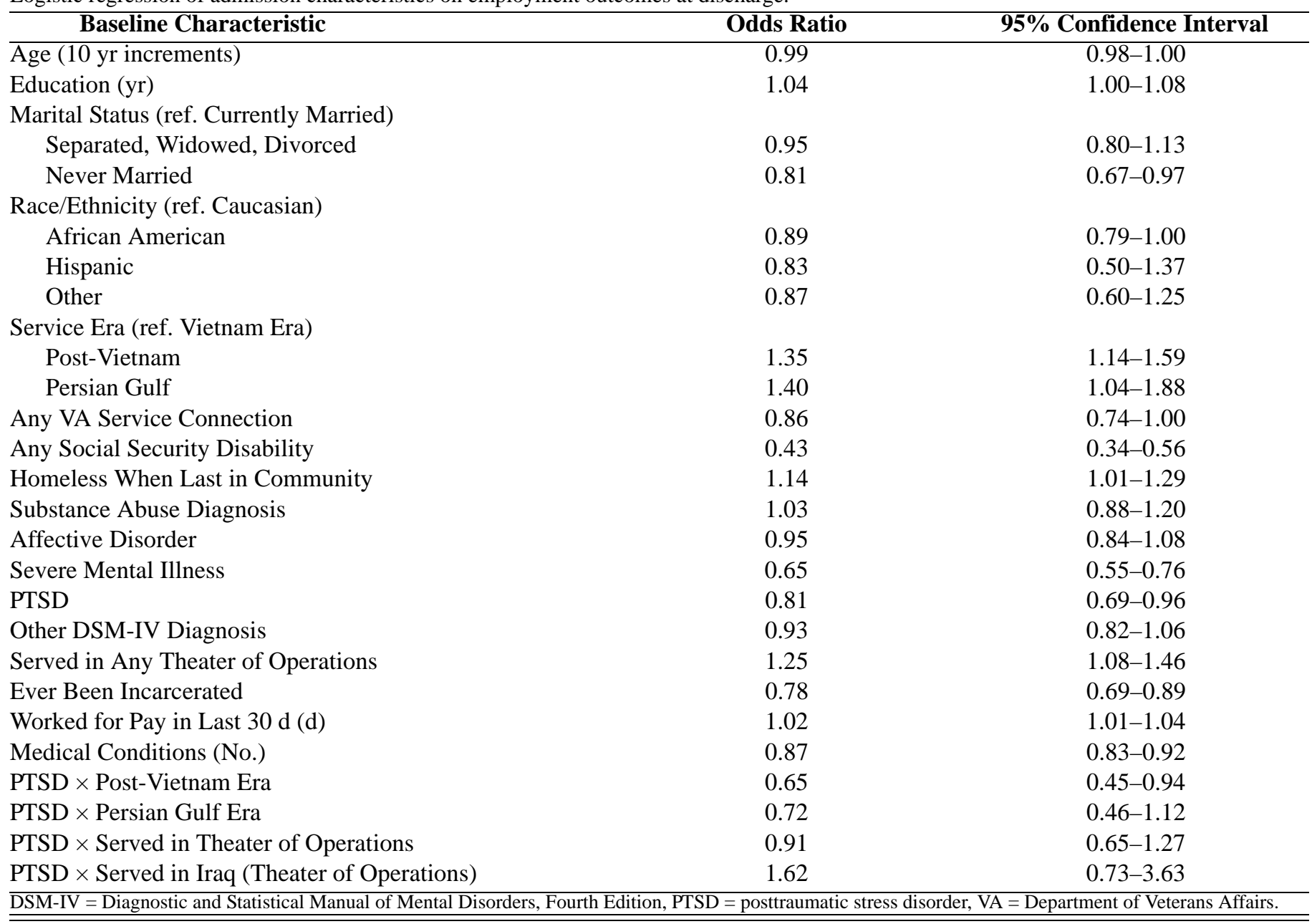


the 90 days prior to discharge between veterans with PTSD $(n=792,85.6 \%)$ and without PTSD $(n=4,277$, 87.3\%; $\chi^{2}(1)=1.87$, not significant). However, of those who worked at all in the 90 days prior to discharge, veterans with PTSD worked significantly fewer days in the 90 days prior to discharge (mean $\pm \mathrm{SD}=33.4 \pm 24.9$ days) than did those without PTSD (mean \pm SD $=36.4 \pm 26.2$ days; $t(5,065)=3.00, p=0.003$ ) by about 11 percent.

\section{DISCUSSION}

In view of the increased attention and concern about the rehabilitation of veterans returning from Iraq and Afghanistan, as well as those from prior eras, this study sought to study employment outcomes and work activity during and after participation in a large VHA vocational rehabilitation program. After controlling for other factors, veterans with PTSD were 19 percent less likely to be competitively employed at discharge from CWT, and of those who worked in their last 90 days of CWT participation, veterans with PTSD worked fewer days compared with individuals without PTSD.

These findings are consistent with past research that demonstrated vocational deficits for veterans with PTSD, including veterans with combat-related PTSD [3-6]. These findings are particularly relevant given concerns about high rates of PTSD among veterans returning from current conflicts [14]. It is particularly noteworthy that in the current study, PTSD was associated with a decreased likelihood of employment, while affective disorders, substance use disorders, and other Diagnostic and Statistical Manual of Mental Disorders-Fourth Edition diagnoses were not. Some potential explanations for this finding may be derived from the symptoms of PTSD. One of the hallmarks of PTSD is the cluster of avoidance symptoms [15], including a sense of a foreshortened future, where the individual may believe that normal life activities such as a career are not available to them. It would follow that one who despairs for the future may not see the logic in obtaining employment. Individuals who experience flashbacks, a symptom of PTSD, may find it difficult to explain to others what is happening to them or may not be functional during these seemingly random episodes. Anger and irritability are also common symptoms [15]. In few workplaces can an individual control the environment sufficiently to minimize the influence of these symptoms, and thus individuals with PTSD may prefer to stay at home or at other places where people and stimuli are predictable.

Although the rate of competitive employment for individuals with PTSD was lower than for those without, the overall rate of employment at discharge was low for both groups, at 30 and 36 percent respectively-a modest difference. This low rate suggests that the recent VA SE initiative, which is targeted primarily at individuals with severe mental illness, may need to be expanded to better meet the needs of veterans with PTSD as well. Although PTSD was associated with reduced likelihood of employment, it is notable that service in a combat theater of operations, which exposes soldiers to increased risk of trauma, was unexpectedly associated with increased rates of employment. To explore this relationship further, we evaluated model interactions between PTSD and service in a theater of operations. These interactions were not significantly associated with employment. The finding that veterans who served in a theater of operations have higher rates of employment remains as an anomalous finding.

Interaction analysis did show that PTSD had a significantly greater adverse effect on employment among veterans of the post-Vietnam era, perhaps because veterans recruited during that time had especially poor employment prospects. The years immediately following the Vietnam War marked the beginning of the all-volunteer military service in the United States, a practice not highly regarded by the public. As a result, those who entered the service often had poorer employment prospects than other young men, along with higher rates of homelessness, substance abuse, and antisocial personality [16] and greater risk of incarceration [17].

Among the other prominent factors that were associated with employment were greater education and prior work history, both commonly found to be predictors of employment in prior studies [18]. Factors associated with reduced employment, also consistent with other studies $[13,19]$, included public support income, the number of medical conditions, and prior incarceration.

In this study, the proportion of veterans who reported being homeless when last in the community was 62 percent, compared with approximately 11 percent among veterans receiving general VA mental health services [20]. One explanation for the overrepresentation of homeless veterans in CWT is the logistical difficulty homeless people experience obtaining employment because of their lack of a mailing address, telephone number, or opportunities 
for grooming and hygiene. Along with vocational support, CWT programs often provide clothing, voice mail services, and other assistance that could be critical in the employment process. While this is a plausible explanation for the high proportion of homeless veterans enrolled in CWT, it does not fully explain why homeless veterans would have better employment outcomes than others. VA has a long history of providing comprehensive services to homeless veterans [21] and so one potential explanation is that CWT staff have special expertise in engaging and assisting homeless veterans.

Several study limitations should be noted. Diagnostic information was obtained by the CWT staff, often from the medical record, and is of undemonstrated validity. Further, employment data is based on veteran self-report, and in some cases, the clinician's closest estimate of the veteran's self-report, and thus may be just an approximation of postdischarge employment rates. Further, findings cannot be generalized to individuals in the general veteran population, only to those participating in CWT.

\section{CONCLUSIONS}

These findings suggest that PTSD is a significant obstacle to employment, even after adjusting for potentially confounding factors including service era and service in various theaters of operations. VHA is currently renewing its commitment to evidence-based mental health treatment, including increased amounts and types of services for individuals with PTSD [22]. With a major expansion of CWT services currently under way in VA [10], a specific expansion of evidence-based SE services for veterans with PTSD may be needed to optimize the employment potential of these most deserving veterans and to foster their return to mainstream community employment.

\section{ACKNOWLEDGMENTS}

This material was based on work supported by VA Health Services Research and Development grant MNT 05-098.

The authors have declared that no competing interests exist.

\section{REFERENCES}

1. President's New Freedom Commission on Mental Health. Achieving the promise: Transforming mental health care in America. Rockville (MD): President's New Freedom Commission on Mental Health; 2003.

2. Bond GR, Jones A. Supported employment. In: Drake RE, Merrens MR, Lynde DW, editors. Evidence-based mental health practice: A textbook. New York (NY): W.W. Norton; 2005.

3. Savoca E, Rosenheck R. The civilian labor market experiences of Vietnam-era veterans: The influence of psychiatric disorders. J Ment Health Policy Econ. 2000;3(4):199-207. [PMID: 11967456]

4. Smith MW, Schnurr PP, Rosenheck RA. Employment outcomes and PTSD symptom severity. Ment Health Serv Res. 2005;7(2):89-101. [PMID: 15974155]

5. Magruder KM, Frueh BC, Knapp RG, Johnson MR, Vaughan JA 3rd, Carson TC, Powell DA, Hebert R. PTSD symptoms, demographic characteristics, and functional status among veterans treated in VA primary care clinics. J Trauma Stress. 2004;17(4):293-301. [PMID: 15462536]

6. Rosenheck R, Stolar M, Fontana A. Outcomes monitoring and the testing of new psychiatric treatments: Work therapy in the treatment of chronic post-traumatic stress disorder. Health Serv Res. 2000;35(1 Pt 1):133-51.

[PMID: 10778827]

7. Mueser KT, Essock SM, Haines M, Wolfe R, Xie H. Posttraumatic stress disorder, supported employment, and outcomes in people with severe mental illness. CNS Spectr. 2004;9(12):913-25. [PMID: 15616477$]$

8. Resnick SG, Baldino R, Corwel L, Medak S, Rosenheck RA. Seventh progress report on the compensated work therapy (CWT)/veterans industries (VI) program: Fiscal year 2003. Report to the United States Congress. West Haven (CT): Northeast Program Evaluation Center; 2004.

9. Becker DR, Drake RE. A working life for people with severe mental illness. New York (NY): Oxford University Press; 2003.

10. Resnick SG, Rosenheck R. Dissemination of supported employment in Department of Veterans Affairs. J Rehabil Res Dev. 2007;44(7):867-78. [PMID: 18075943]

11. Greenberg GA, Rosenheck RA. Compensation of veterans with psychiatric and substance abuse disorders and employment and earnings. Mil Med. 2007;172(2):162-68. [PMID: 17357771]

12. Resnick SG, Rosenheck RA, Drebing CE. What makes vocational rehabilitation effective? Program characteristics versus employment outcomes nationally in VA. Psychol Serv. 2006;3(4):239-48.

13. Rosenheck R, Frisman L, Sindelar J. Disability compensation and work among veterans with psychiatric and nonpsychiatric 
impairments. Psychiatr Serv. 1995;46(4):359-65. [PMID: 7788457]

14. Hoge CW, Castro CA, Messer SC, McGurk D, Cotting DI, Koffman RL. Combat duty in Iraq and Afghanistan, mental health problems, and barriers to care. N Engl J Med. 2004; 351(1):13-22. [PMID: 15229303]

15. American Psychiatric Association. Diagnostic and Statistical Manual of Mental Disorders, Fourth Edition. Washington (DC): American Psychiatric Association; 1994.

16. Rosenheck R, Frisman L, Chung AM. The proportion of veterans among homeless men. Am J Public Health. 1994; 84(3):466-69. [PMID: 8129068]

17. Greenberg GA, Rosenheck RA, Desai RA. Risk of incarceration among male veterans and nonveterans: Are veterans of the all volunteer force at greater risk? Armed Forces Soc. 2007;33(3):337-50.

18. Razzano LA, Cook JA, Burke-Miller JK, Mueser KT, Pickett-Schenk SA, Grey DD, Goldberg RW, Blyler CR, Gold PB, Leff HS, Lehman AF, Shafer MS, Blankertz LE, McFarlane WR, Toprac MG, Ann Carey M. Clinical factors associated with employment among people with severe mental illness: Findings from the employment intervention demonstration program. J Nerv Ment Dis. 2005;193(11): 705-13. [PMID: 16260923]

19. Drew D, Drebing CE, Van Ormer A, Losardo M, Krebs C, Penk W, Rosenheck RA. Effects of disability compensation on participation in and outcomes of vocational rehabilitation. Psychiatr Serv. 2001;52(11):1479-84. [PMID: 11684743]

20. Rosenheck RA, Mares AS. Implementation of supported employment for homeless veterans with psychiatric or addiction disorders: Two-year outcomes. Psychiatr Serv. 2007;58(3):325-33. [PMID: 17325104]

21. Kasprow WJ, Rosenheck RA, DiLella D, Cavallaro L, Harelik N. Health care for homeless veterans programs: Twentieth annual report. West Haven (CT): Northeast Program Evaluation Center Report to Congress; 2007.

22. Fontana A, Rosenheck R, Spencer H, Gray S. Long journey home XIV: Treatment of posttraumatic stress disorder in the Department of Veterans Affairs: Fiscal year 2005 service delivery and performance. West Haven (CT): Northeast Program Evaluation Center; 2006.

Submitted for publication June 27, 2007. Accepted in revised form September 11, 2007. 